\title{
Projeto conceitual de componentes de um forno industrial por meio da integração entre a engenharia reversa e o DFMA
}

\section{Conceptual design of components of an industrial oven through the integration between the reverse engineering and DFMA}

\author{
Carlos Henrique Pereira Mello² \\ Filipe Natividade Guedes ${ }^{1}$ \\ Carlos Eduardo Sanches da Silva ${ }^{2}$ \\ José Hamilton Chaves Gorgulho Júnior ${ }^{2}$ \\ Amanda Fernandes Xavier ${ }^{3}$
}

\begin{abstract}
Resumo: O tema deste artigo é o estudo da integração da engenharia reversa (ER) e o projeto para manufatura e montagem (DFMA) como ferramentas de suporte ao projeto conceitual de produtos. A partir de uma fundamentação teórica sobre esses conceitos, o presente trabalho visa analisar a adequação de um modelo para a utilização integrada do DFMA com a prototipagem rápida em uma abordagem de ER no projeto de um novo sistema de fechadura para forno industrial e recomendar melhorias no projeto conceitual do novo sistema de fechadura. O método de pesquisa empregado foi a pesquisa-ação, uma vez que o pesquisador buscava resolver um problema identificado dentro do objeto de estudo em parceria com a equipe de profissionais da empresa. Os resultados das recomendações para o projeto conceitual apresentam redução, especialmente, no custo, no tempo para fabricação e no tempo para montagem. Conclui-se que o modelo de integração estudado foi adequado para apoiar o processo de projeto do sistema de fechadura proposto por meio da ER.
\end{abstract}

Palavras-chave: Engenharia reversa. Processo de desenvolvimento de produtos. Projeto conceitual. Projeto para manufatura e montagem.

\begin{abstract}
This study focuses on investigating the integration between reverse engineering (RE) and design for manufacture and assembly (DFMA) as tools to support the conceptual design of products. From a literature review of these concepts, this research aims to examine the adequacy of a model for the integrated use of DFMA and rapid prototyping in an ER approach in the design of a new locking system for an industrial oven and recommend improvements in conceptual design of a new lock system. The research method employed was action-research since the aim was to solve a problem identified in the company, object of study, in partnership with the company team. The results of the conceptual design indicate reductions, especially in cost, time to manufacture, and assembly time. It was concluded that the integration model studied was adequate to support the design process of the locking system proposed by the ER approach.
\end{abstract}

Keywords: Reverse engineering. Product development process. Conceptual design. Design for manufacturing and assembly.

\section{Introdução}

Cada vez mais o mercado tem imposto aos produtos especificações que vêm se desenvolvendo e se atualizando de forma muito rápida. As empresas

sabem que, para se manter no mercado, são obrigadas a aprender a analisar e atender a essas necessidades a uma velocidade muitas vezes maior que o

\footnotetext{
${ }^{1}$ Graduando em Engenharia de Produção, Núcleo de Otimização da Manufatura e de Tecnologia da Inovação - NOMATI, Instituto de Engenharia de Produção e Gestão - IEPG, Universidade Federal de Itajubá - UNIFEI, CP 50, CEP 37500-000, Itajubá, MG, Brasil, E-mail: filipenatividade@yahoo.com.br

${ }^{2}$ Professor Adjunto, Doutor, Núcleo de Otimização da Manufatura e de Tecnologia da Inovação - NOMATI, Instituto de Engenharia de Produção e Gestão - IEPG, Universidade Federal de Itajubá - UNIFEI, CP 50, CEP 37500-000, Itajubá, MG, Brasil, E-mail: carlos.mello@unifei.edu.br; sanches@unifei.edu.br; gorgulho@unifei.edu.br

${ }^{3}$ Mestranda em Engenharia de Produção, Núcleo de Otimização da Manufatura e de Tecnologia da Inovação - NOMATI, Instituto de Engenharia de Produção e Gestão - IEPG, Universidade Federal de Itajubá - UNIFEI, CP 50, CEP 37500-000, Itajubá, MG, Brasil, E-mail: amandaxavier@unifei.edu.br
} 
próprio surgimento delas (HUANG; MAK, 1998; SALGADO et al., 2009). Melhorar um produto implica em oferecer novas características, tecnologias, formas atrativas melhorar a qualidade para o seu lançamento no mercado (GAUTAM; SINGH, 2008). Desta forma, técnicas para análise do mercado são utilizadas para auxiliar na interpretação do que o mercado está necessitando ou do que ele ainda necessitará.

Os clientes aguardam pelo lançamento de novos produtos, preferencialmente, no menor tempo possível. Alguns desses clientes esperam a sua marca preferida lançar um novo produto. Na realidade, o tempo de renovação de seus produtos e o potencial de renovação de modelos e diversificação das versões passou a ser mais uma das características que ajudam a redefinir o conceito de marca preferida. Este ritmo acelerado das exigências dos consumidores obriga as empresas a manterem seus produtos atualizados e competitivos no mercado e, consequentemente, o seu processo de desenvolvimento. Para alcançarem estes resultados, os produtos precisam ser constantemente melhorados com base nas necessidades dos consumidores.

Dufour (1996) é enfático ao dizer que muitos dos novos projetos, mesmo que inconscientemente, são na maioria dos casos, reprojetos baseados em um produto já existente. Porém, esta atividade não pode ser realizada, unicamente, de forma intuitiva, dependendo apenas do empirismo. $\mathrm{O}$ reprojeto necessita ser realizado por meio de um processo sistematizado, que oriente o trabalho do projetista e da equipe de desenvolvimento de produtos, desde a identificação do problema até o projeto final do produto, oferecendo maiores possibilidades de sucesso.

No caso das pequenas e médias empresas, Silva (2001) pondera que, para este tipo de empresa, ser considerado como pioneiro no desenvolvimento de produtos não é um dos fatores críticos de sucesso. Então, adiciona-se a esta análise o estudo da montabilidade e manufaturabilidade, pela avaliação estruturada das condições e dos recursos produtivos disponíveis, interna e externamente, como forma de redução de custos imprevistos e otimização dos prazos para lançamento de produtos. Sendo assim, o reprojeto dos produtos, apoiado por uma abordagem de engenharia reversa (ER) integrada ao projeto para manufatura e montagem (DFMA), pode ser uma forma de essas empresas conseguirem lançar novos produtos com menores investimento e risco.

O presente trabalho identificou um problema de pesquisa em uma pequena empresa de bens de consumo para fins alimentícios, consolidada no mercado de fornos industriais e que apresentou oportunidade de melhorar todo o sistema de fechamento da porta de um de seus modelos. O novo sistema necessita permitir sua utilização para qualquer tipo de fechamento, principalmente geladeiras e fornos, devido à semelhança de características para seu manuseio de abertura e fechamento. A fechadura precisa atender a uma característica básica que é a perfeita selagem da câmara, mesmo após ser aberta e fechada inúmeras vezes. A partir de então, todo o resto depende da tecnologia do mecanismo. Além disso, a empresa ainda não possui um processo consolidado para o reprojeto de seus produtos.

Para resolver o problema de pesquisa identificado, definiu-se como objetivos do trabalho: analisar a adequação de um modelo para a utilização integrada do projeto para manufatura e montagem (DFMA) com a prototipagem rápida em uma abordagem da engenharia reversa (ER) no projeto de um novo sistema de fechadura para forno industrial; e recomendar melhorias no projeto conceitual do novo sistema de fechadura.

O método de pesquisa empregado foi a pesquisaação. Segundo Thiollent (2007), a pesquisa-ação é um tipo de pesquisa social com base empírica que é concebida e realizada em estreita associação com uma ação ou com a resolução de um problema coletivo e no qual os pesquisadores e os participantes representativos da situação ou do problema estão envolvidos de modo cooperativo ou participativo.

\section{Fundamentação teórica}

\subsection{Processo de desenvolvimento de produtos}

Segundo Toledo et al. (2008), o processo de desenvolvimento de produto (PDP) é considerado, cada vez mais, um processo crítico para a capacidade competitiva das empresas, tendo em vista a necessidade, de um modo geral, de renovação frequente das linhas de produtos, redução dos custos e prazos de desenvolvimento, desenvolvimento de produtos mais adequados às necessidades do mercado e, para empresas que participam de redes de fornecimento de componentes e sistemas, capacitação para participar de estratégias de desenvolvimento conjunto (co-design) com os clientes.

Para Rozenfeld et al. (2006), desenvolver produtos consiste em um conjunto de atividades por meio das quais se busca, a partir das necessidades do mercado e das possibilidades e restrições tecnológicas, e considerando as estratégias competitivas e de produto da empresa, chegar a especificações de projeto de um produto e de seu processo de produção para que a manufatura seja capaz de produzi-lo.

A inovação é fundamental para o desenvolvimento da sociedade, rejuvenescimento, crescimento de negócios e críticas para a sobrevivência, a longo prazo, de uma empresa no mundo dos negócios. Também é reconhecido que a inovação é mais do que a invenção de novos produtos, mas um complexo conceito multidimensional, que deve ser visto de 
diferentes perspectivas, no seu contexto específico (HÜSIG; KOHN, 2009).

Muitos produtos são feitos de componentes distintos que, por si só, não têm nenhuma influência para os consumidores finais. Na indústria automobilística, por exemplo, alguns componentes de sistemas do carro como, motor, sistema de freio, sistema de suspensão, são usados para apenas um único veículo. Normalmente, um componente distinto pode ser usado para produzir sistemas de carros diferentes, desde que as interfaces relevantes sejam padronizadas. É por isso que empresas diferentes (que podem ou não ser concorrentes), muitas vezes acordam em desenvolver alguns componentes do produto por meio da cooperação (BOURREAU; DOGAN, 2009).

Sobre os modelos de desenvolvimento de produtos, Ogliari (1999) cita que é possível encontrar diversos tipos disponíveis na literatura (BACK, 1983; ROSENTHAL, 1992; VINCENT, 1989; WHEELWRIGHT; CLARK, 1992; COOPER; EDGETT, 1999; PAHL et al., 2005; ROZENFELD et al., 2006; BACK et al., 2008), e a principal diferença entre eles ocorre normalmente nas denominações de suas fases, mantendo-se quase que constantes as suas sequências e conceitos.

Pahl et al. (2005) mencionam um modelo de desenvolvimentos de produtos (Figura 1) que destaca os aspectos importantes para a implantação da engenharia simultânea, considerando basicamente a antecipação e intersecção do início das fases para uma redução do prazo para o desenvolvimento de um novo produto e de acompanhamento de seus custos. Na Figura 1 foi destacada a utilização do DFMA.

No processo de criação de um produto sob a ótica da engenharia simultânea, as atividades de cada um dos departamentos da empresa caminham, em grande parte, em paralelo. Ocorre também um permanente monitoramento do produto até o fim do seu ciclo de vida. Pahl et al. (2005) ressaltam a importância da equipe de desenvolvimento ser constituída não somente por pessoas responsáveis diretamente pelo projeto, mas também por outros setores que estejam envolvidos com o desenvolvimento de produtos, para que os aspectos ligados ao processo possam ser tratados de forma a romper as fronteiras departamentais.

Visto que, em geral, a condição das pequenas e médias empresas (PMEs) não é necessariamente a de pioneirismo e que suas estratégias de desenvolvimento de produtos não são necessariamente ofensivas (SILVA, 2001), devido à necessidade de grandes investimentos em pesquisa e desenvolvimento tecnológico, muitas vezes, este entendimento e uma revisão na estratégia passam a ser o ponto chave para a redução de custos ou, até mesmo, a possibilidade única de desenvolvimento de novos produtos de uma forma estruturada e com maiores chances de sucesso. Dessa forma, a abordagem da engenharia reversa para o processo de desenvolvimento de produtos passa a ser uma possível solução para a inovação nessas empresas.

\subsection{Engenharia reversa}

A engenharia reversa (ER) é uma ferramenta muito importante, e esta técnica tem sido amplamente reconhecida como sendo um passo importante no ciclo de desenvolvimento de produtos. O uso da ER diminui o tempo e os custos para chegar-se ao novo produto. Em contraste com as sequências tradicionais de desenvolvimento de produtos, a engenharia reversa normalmente começa com a medição de um produto de referência, de modo que um modelo sólido pode ser deduzido, a fim de fazer uso das vantagens tecnológicas existentes. Posteriormente, modelos são utilizados para a fabricação ou prototipagem rápida (BAGCI, 2008).

Segundo Kim e Nelson (2000), países com a industrialização recente recorreram, principalmente nas décadas de 1960 e 1970, à engenharia reversa. Zhu, Liang e Xu (2005) afirmam que o processo de aquisição de tecnologia da China segue, geralmente, a seguinte linha: aquisição de linhas de manufatura e técnicas de países desenvolvidos, modificação do processo e identificação das partes e componentes, alcançar o desenvolvimento do produto por meio da ER e, por fim, otimizar os produtos. O processo de inovação da Coreia do Sul é por meio da ER, esperando

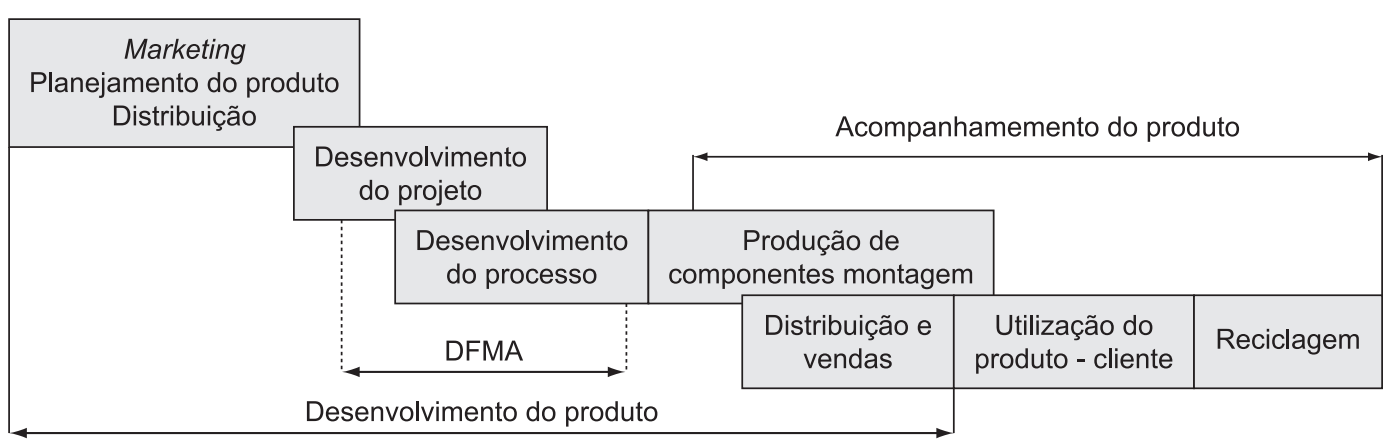

Figura 1. Modelo de referência para o PDP. Fonte: Pahl et al. (2005). 
os países desenvolvidos gerarem novas tecnologias e mercados para, aí sim, desenvolver seus produtos (HOBDAY; RUSH; BESSANT, 2004).

A ER é útil para orientar o entendimento do sistema de interesse e permitir que sejam feitas comparações com modelos de design semelhantes para verificar o que realmente pode ser aproveitado da tecnologia (KANG; PARK; WU, 2009).

Ingle (1994) define a ER como um processo de levantamento de informações sobre um produto de referência por meio da sua desmontagem, com o objetivo de determinar como ele foi desenvolvido, desde seus componentes separados até o produto final. Sua abordagem defende claramente a aplicação da ER com o objetivo de gerar um produto o mais similar possível ao original com um nível de investimento que possa garantir a geração de lucros ao empreendimento.

A principal aplicação da ER é no reprojeto e aperfeiçoamento de peças já existentes, em que sejam desejadas melhorias, tais como redução de custo ou mesmo inclusão de novas características ao produto. Além disso, um projeto de ER permite, por meio da construção de peças de reposição, fora de linha ou de difícil acesso, manter equipamentos obsoletos em funcionamento (MURY, 2000).

Apesar de muito citado na literatura, o modelo de Ingle (1994) não contempla a integração do projeto para manufatura e montagem com a prototipagem rápida em uma abordagem de engenharia reversa para o reprojeto de produtos. Essa é uma contribuição científica que o presente trabalho busca oferecer.

Outra abordagem que, de forma integrada com a ER, pode auxiliar a análise de reprojeto de produtos é o projeto para manufatura e montagem (DFMA).

\subsection{Projeto para manufatura e montagem}

Dentre os métodos de apoio ao design de produtos que auxiliam a considerar a fabricação e montagem, durante a fase de concepção, o DFMA é utilizado como apoio para melhorar o conceito do produto ou um projeto já existente. Afinal, o foco do DFMA é contribuir para gerar um projeto considerando a capacidade de fabricação da empresa, para facilitar a montagem do produto final (ESTORILIO; SIMIÃO, 2006).

O DFMA visa que o projeto de produto e o planejamento da produção aconteçam simultaneamente a partir de um conjunto de princípios. Já no reprojeto, o DFMA ajuda a adequar o produto da melhor maneira às características da produção e montagem, procurando melhorar a qualidade e reduzir o tempo de manufatura e montagem (DUFOUR, 1996).

Segundo Stephenson e Wallace (1995) e Boothroyd, Dewhurst e Knight (2002), os requisitos da concepção original devem ser reavaliados para estabelecer os novos requisitos de qualidade DFMA, considerando sempre os seguintes princípios básicos do projeto para manufatura (DFM) e do projeto para montagem (DFA): simplicidade (diminuir o número de partes, sequência de manufatura mais curta etc.); materiais e componentes padronizados; liberar tolerâncias (evitar tolerâncias muito justas, que implicam em custos altos); uso de materiais mais processáveis; reduzir operações secundárias; utilizar características especiais de processo (tirar vantagem das capacidades especiais dos processos de manufatura, eliminando operações onerosas e desnecessárias); evitar limitações no processo.

\subsection{Prototipagem rápida}

A prototipagem rápida $(\mathrm{PR})$ é uma tecnologia inovadora desenvolvida nas últimas duas décadas. Ela visa produzir protótipos de forma relativamente rápida para inspeção visual, avaliação ergonômica, análise de forma/dimensional e como padrão mestre para a produção de ferramentas para auxiliar na redução de tempo do processo de desenvolvimento de produtos (CHOI; CHAN, 2004). A PR permite aos projetistas criar rapidamente protótipos concretos a partir de seus projetos, ao invés de Figuras bidimensionais, possibilitando um auxílio visual excelente durante a discussão prévia do projeto com colaboradores ou clientes.

Atualmente existe um grande número de tecnologias de prototipagem rápida disponíveis no mercado. Entretanto, sete delas se destacam: estereolitografia (SLA), sinterização seletiva a laser (SLS), manufatura de objetos em lâminas (LOM), modelagem por deposição de material fundido (FDM) e impressão tridimensional (3D Printing) (CHEN, 2000).

A presente pesquisa se concentrou na tecnologia de modelagem por deposição de material fundido (Fused Deposition Modelling - FDM), por ser aquela que oferece equipamentos de menor custo (KOCHAN, 2000), ou seja, ao alcance das pequenas e médias empresas e das instituições de pesquisa.

A FDM se baseia na deposição, sobre uma plataforma, de camadas resultantes do aquecimento e amolecimento de filamentos do material plástico destinado à confecção do modelo, como ilustra a Figura 2. Simultaneamente, outros fios amolecidos vão formando suportes para as superfícies livremente suspensas do modelo, a fim de que elas possam ser construídas. Os arames destinados ao modelo são, geralmente, de ABS (Acrylonitrile Butadiene Styrene), enquanto os destinados aos suportes são uma mistura de ABS e cal.

A partir do protótipo gerado, a equipe de projeto pode analisar o produto adotado como referência, testar suas especificações, testar situações de manufatura ou montagem, propor alterações dimensionais ou construtivas e estabelecer as possíveis melhorias a serem feitas no produto final a ser desenvolvido. 


\subsection{Integração da engenharia reversa com o projeto para manufatura e montagem}

No processo de criação de um produto, sob a ótica da engenharia simultânea, as atividades de cada um dos departamentos da empresa caminham, em grande parte, em paralelo. Ocorre também um permanente monitoramento do produto até o fim do seu ciclo de vida.

Partindo-se do modelo analisado por Pahl et al. (2005) (Figura 1), Souza (2007) propôs uma adaptação no modelo para a inclusão das considerações realizadas por Ingle (1994), de forma que se contemple o desenvolvimento de produtos em uma abordagem de engenharia reversa.

Depois de realizada a inclusão do processo de engenharia reversa, é necessário deixar as fases de forma clara dentro do modelo. Analisando-se o trabalho proposto por Ingle (1994), observa-se que existe uma grande deficiência nas considerações relativas às necessidades da manufatura e montagem. Desta forma, o modelo proposto por Souza (2007), considera que os fundamentos do DFMA sejam incluídos durante as análises de engenharia reversa, fazendo com isto um complemento ao proposto por Ingle (1994). A partir da análise dessas necessidades, Souza (2007) gerou um modelo composto por oito etapas, como ilustra a Figura 3.

Esse modelo não busca substituir todas as fases inicialmente propostas por Pahl et al. (2005), mas sim as fases específicas de desenvolvimento do projeto e do processo. Ou seja, esta adaptação busca otimizar a parte técnica do processo de desenvolvimento de um produto, de forma que ele poderá ser aplicado a outros modelos existentes, inclusive de reprojeto de um produto, esperando-se que os mesmos resultados finais possam ser obtidos.

O Quadro 1 apresenta um breve detalhamento de cada uma das fases do referido modelo.

\section{Pesquisa-ação}

\subsection{Descrição do método}

Bryman (1989) considera que a pesquisa-ação é uma abordagem da pesquisa social aplicada, na qual o pesquisador e o cliente colaboram no desenvolvimento de um diagnóstico e para a solução de um problema, por meio da qual as descobertas resultantes irão contribuir para a base de conhecimento em um domínio empírico particular.

De modo geral, esta abordagem de pesquisa compreende três fases principais: uma preliminar, um ciclo de condução e uma meta-fase, ilustradas na Figura 4. O ciclo de condução da pesquisa compreende

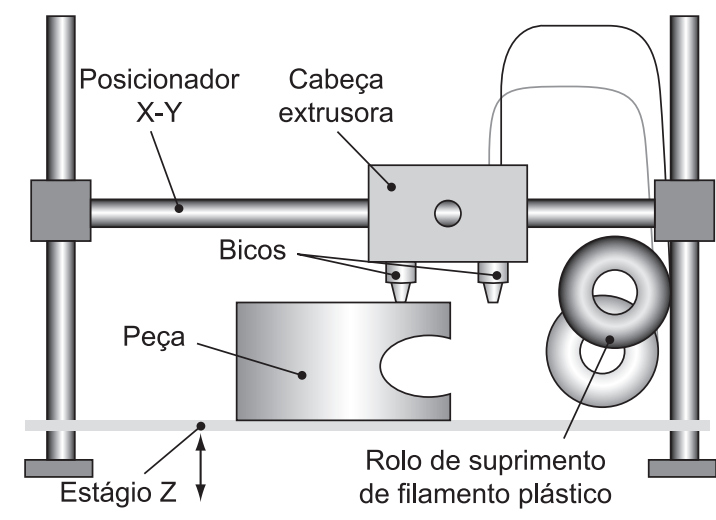

Figura 2. O processo de modelagem por deposição de material fundido. Fonte: Artis (2006).

seis passos, enquanto que a meta-fase está presente em cada um desses seis passos.

A fase do estudo preliminar no presente trabalho compreendeu reuniões de planejamento, realizadas com o intuito de identificar os problemas no sistema de fechamento de um forno industrial, por meio de informações fornecidas pelos próprios clientes e análise do mercado. Assim, o seguinte propósito foi estabelecido: desenvolver um sistema de fechadura, de fácil utilização se comparado ao atual, para o forno modelo EC-10.

Na segunda fase, o ciclo de condução constituído por seis passos (Figura 3), foi repetido 12 vezes, como mostra o Quadro 2. Alguns ciclos foram mais longos do que os demais, tais como os ciclos 5 e 9 , em que foi necessário projetar as peças no software SolidWorks (versão 2005) e usinar as peças em metal, respectivamente.

$\mathrm{Na}$ terceira (meta) fase, denominada de monitoramento, foi realizada a verificação de cada um dos seis passos anteriores, no sentido de identificar qual é o aprendizado gerado na condução da pesquisa-ação. O monitoramento gerou diversas lições aprendidas que foram registradas na base de dados da empresa para serem utilizadas em projetos futuros.

\subsection{Descrição da pesquisa}

A unidade de análise selecionada para o presente trabalho foi a Prática Technicook. Ela foi fundada em 1991, está situada em Pouso Alegre (MG), e desde 1994 fabrica com sucesso fornos para panificação e para cozinhas industriais. A empresa é líder nacional no segmento dos fornos para cozinhas profissionais, sendo referência no mercado em que atua.

A pesquisa, realizada de janeiro a setembro de 2009, seguiu as etapas do modelo de integração proposto por Souza (2007), citados no item 2.5, apresentadas a seguir. 
Quadro 1. Etapas do modelo proposto por Souza (2007).

\begin{tabular}{|c|c|}
\hline Etapa & Significado \\
\hline Identificar a oportunidade & $\begin{array}{l}\text { Identificar e reconhecer a posição em que a empresa se encontra no mercado } \\
\text { em que atua e identificar qual é o produto a ser considerado como referência. }\end{array}$ \\
\hline $\begin{array}{l}\text { Coletar e preparar as } \\
\text { informações iniciais }\end{array}$ & $\begin{array}{l}\text { Obter um levantamento inicial do mercado não somente do produto de } \\
\text { referência, mas de todos que podem compor um nível de conhecimento } \\
\text { sobre a classe de produtos que se está analisando. Coletar e dispor todas } \\
\text { as informações que possam contribuir para a aplicação da engenharia } \\
\text { reversa e da sua integração com os princípios do projeto para a manufatura } \\
\text { e montagem (DFMA). }\end{array}$ \\
\hline $\begin{array}{l}\text { Formação da equipe } \\
\text { multifuncional }\end{array}$ & $\begin{array}{l}\text { A equipe multidisciplinar de desenvolvimento necessita conter elementos } \\
\text { que detêm o conhecimento teórico e prático sobre todos os detalhes e } \\
\text { características do produto produzido pela empresa, e estes conhecimentos } \\
\text { devem estar disponíveis para toda a equipe, para que nenhuma oportunidade } \\
\text { passe despercebida. }\end{array}$ \\
\hline $\begin{array}{l}\text { Desmontar (coletar } \\
\text { informações do produto) }\end{array}$ & $\begin{array}{l}\text { Analisar tecnicamente os sistemas de forma sistemática e as funções } \\
\text { envolvidas em cada um dos componentes e subsistemas do produto de } \\
\text { referência (ou dos produtos) para se disponibilizar informações que serão } \\
\text { analisadas mais detalhadamente na fase seguinte. É necessário ter uma } \\
\text { preocupação principal na interação entre os componentes, com uma visão } \\
\text { muito focada em detalhes técnicos (tolerâncias, fixações, ajustes etc.). }\end{array}$ \\
\hline $\begin{array}{l}\text { Medir e testar (coletar } \\
\text { informações dos componentes) }\end{array}$ & $\begin{array}{l}\text { As ações realizadas nesta fase estão ligadas à medição e realização de } \\
\text { testes dos componentes do produto de referência, procurando esclarecer as } \\
\text { dúvidas relativas às tecnologias de produto e de processo empregadas no } \\
\text { conjunto e nos componentes. }\end{array}$ \\
\hline Especificar e documentar & $\begin{array}{l}\text { Documentar tecnicamente as informações levantadas na fase anterior } \\
\text { e especificar novas que foram deixadas para esta fase por pessoas mais } \\
\text { ligadas diretamente aos detalhamentos de componentes e processos de } \\
\text { produção. Nesta fase, os princípios do DFMA são utilizados no sentido de } \\
\text { melhorar os aspectos da manufatura e montagem do produto. }\end{array}$ \\
\hline Prototipar & $\begin{array}{l}\text { Utilizar os protótipos (rápidos) dentro do ambiente da engenharia reversa, } \\
\text { para auxílio como fonte de entrada de informações nas análises de DFMA. }\end{array}$ \\
\hline Revisar os resultados & $\begin{array}{l}\text { Realizar um gerenciamento sobre todas as fases anteriores e de como } \\
\text { o processo está caminhando em relação a prazos e custos. Esta fase é } \\
\text { conduzida pelo pesquisador coordenador do projeto e deve ser utilizada } \\
\text { como centralizadora das informações. Após análise do protótipo, } \\
\text { novamente os princípios do DFMA são utilizados para otimização da } \\
\text { solução para o reprojeto do produto. }\end{array}$ \\
\hline
\end{tabular}

Fonte: Adaptado de Souza (2007).

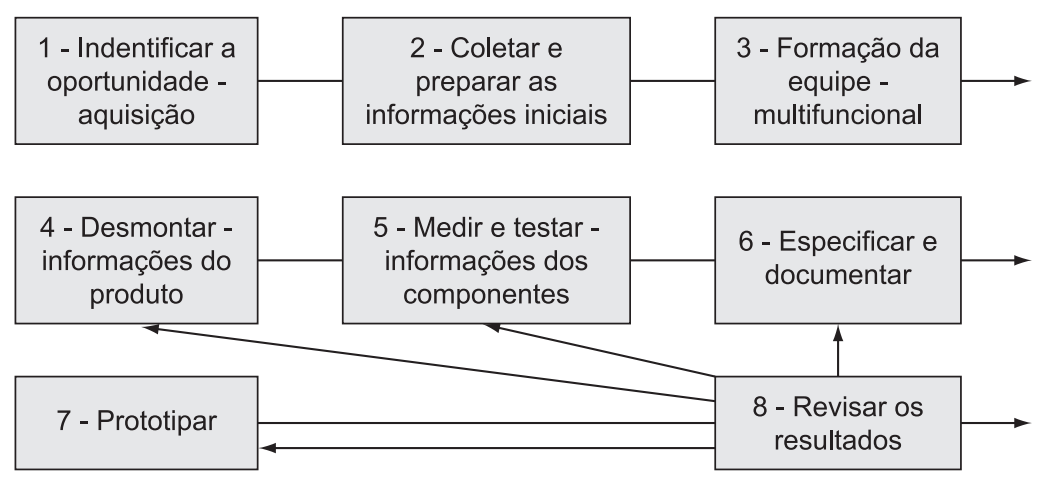

Figura 3. Modelo proposto para desenvolvimento de produtos com o uso do DFMA no processo de ER. Fonte: Souza (2007). 
Quadro 2. Resumo dos ciclos da pesquisa-ação realizada.

\begin{tabular}{|c|c|}
\hline Ciclo & Descrição \\
\hline 1 & $\begin{array}{l}\text { Checaram-se os tipos de fechadura utilizados na empresa, obtiveram-se os desenhos } \\
\text { virtuais, o acesso às fechaduras, a seu desmonte e coletou-se a maior quantidade de } \\
\text { dados possível. }\end{array}$ \\
\hline 2 & $\begin{array}{l}\text { Entrevistou-se o Cozinheiro Chefe da empresa, questionando-o quanto aos sistemas } \\
\text { atuais de fechadura da fábrica: Qual o melhor? Quais os pontos positivos e negativos } \\
\text { de cada um? Atendem ou não às expectativas esperadas do sistema? O que poderia } \\
\text { mudar? Qual seria um bom diferencial? }\end{array}$ \\
\hline 3 & $\begin{array}{l}\text { Buscou-se o maior número de informações quanto aos fornos industriais existentes } \\
\text { no mercado. Conseguiram-se fechaduras de referência para análise, de acordo com a } \\
\text { engenharia reversa. }\end{array}$ \\
\hline
\end{tabular}

4 Desmontaram-se as fechaduras de referência e aprendeu-se como os sistemas funcionam. Identificaram-se os processos de fabricação e perceberam-se as facilidades e dificuldades para montagem e desmontagem. Enfim, juntaram-se todos os dados coletados para iniciar o projeto do novo sistema.

5 Com auxílio do software SolidWorks, iniciou-se o projeto das peças, levando em conta todas as informações coletadas, além de fazer uso dos princípios do DFMA, para garantir facilidades para fabricação das peças e para montagem.

6 Depois de concluídos, os desenhos foram apresentados para o Gerente de Engenharia e Cozinheiro Chefe, para a aprovação do mecanismo. Modificaram-se os itens requisitados e, por fim, chegou-se a um projeto conceitual ideal.

$7 \quad$ Foram prototipadas as peças para testes.

8 Fez-se a montagem do protótipo híbrido e verificou-se a validade do mecanismo. Apresentou-se este para o Gerente de Engenharia e Cozinheiro Chefe. Analisaramse as possíveis necessidades de alterações. Fizeram-se as alterações necessárias no

Desenvolver um sistema de fechadura, de fácil utilização, comparado ao atual, para o forno modelo EC-10.

9 Solicitou-se a fabricação, por usinagem, das peças em metal e amostras das molas para o Responsável de Compras.

10 Construiu-se uma porta com o encaixe necessário para a realização dos testes com o novo sistema de fechadura. Disponibilizou-se um forno para testes. Montouse a fechadura na porta construída e no forno disponibilizado. Foram necessários alinhamentos e regulagens dos componentes. Testou-se o mecanismo diversas vezes. Apresentaram-se os resultados para os Diretores da Fábrica, Gerente de Engenharia, Cozinheiro Chefe e Responsável de Compras.

11 Foram identificados problemas e possíveis necessidades de melhorias. Contataramse as empresas que produziram as amostras de molas e usinagem das peças, para melhorar resultados com as molas e simplificar a usinagem. A empresa de usinagem foi visitada para contato com o responsável e criação de metas de melhorias.

12 Definiu-se, finalmente, o produto. Foram produzidos mais protótipos da fechadura. Foram criados dispositivos pneumáticos para testes de desgaste dos protótipos. Negociaram-se preços para produção em larga escala e foi solicitada a produção das fechaduras nos processos de fabricação mais indicados para cada peça.

\subsubsection{Identificar a oportunidade}

Foram identificados dois fornos de referência. Um proveniente de uma empresa alemã, concorrente direta no Brasil, e outro de uma empresa italiana, que faz a comercialização de diferentes produtos, inclusive fechaduras. Também foram utilizados para fins de comparação todos os quatro diferentes tipos de fechadura usados atualmente na empresa.

Quanto à aquisição, não houve problemas, pois o forno alemão já havia sido adquirido anteriormente pela fábrica, também com o intuito de fazer uso da técnica de ER para outras partes do forno. A fechadura italiana foi fornecida pela própria empresa fabricante, 


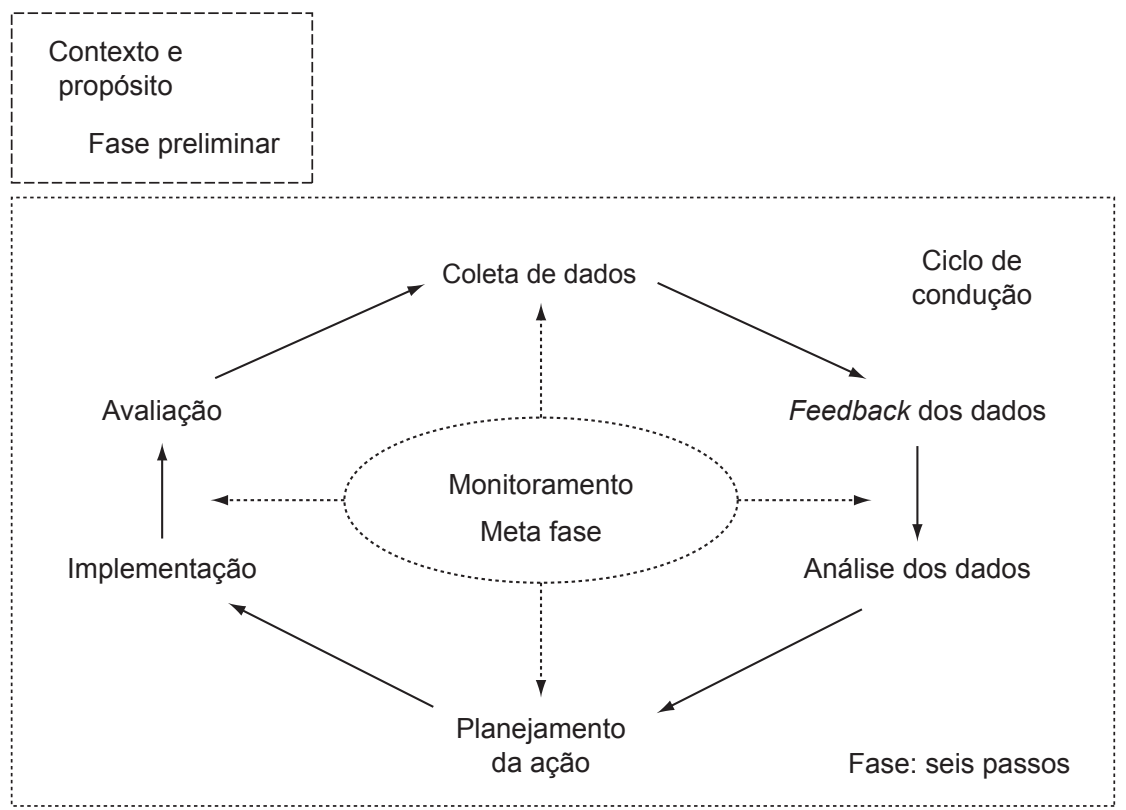

Figura 4. Abordagem da pesquisa-ação empregada. Fonte: Coughlan e Coghlan (2002).

como amostra para possíveis vendas futuras. Dessa forma, não houve custo algum.

\subsubsection{Coletar e preparar dados iniciais}

Todas as informações foram coletadas por um colaborador e dentro da própria empresa, já que havia a disponibilidade da fechadura alemã e da italiana, além das fechaduras usadas na fábrica.

Para se obter outras informações foram consultados os chefes de cozinha, funcionários da assistência técnica, funcionários da engenharia de produto, gerentes, diretores e coletados dados do SAC (Serviço de Atendimento ao Cliente), além de buscas pela internet.

\subsubsection{Formação da equipe}

A equipe de pesquisa formada foi composta pelo Cozinheiro Chefe, Gerente de Engenharia, Diretores da Fábrica e Responsável de Compras, além do pesquisador, os quais supriram as necessidades de informações em diferentes áreas. Cada um dos participantes da empresa tem mais de cinco anos de experiência no desenvolvimento e fabricação dos fornos.

\subsubsection{Desmontar (informações sobre o produto)}

Para as fechaduras usadas na empresa, foram utilizados seus desenhos virtuais, o que possibilitou analisar cada uma quanto à montagem e também cada peça separadamente, sem precisar desmontar o produto.

Já com a fechadura alemã e a italiana, foi realizada a desmontagem, a análise e, por meio de fotografias, o conteúdo pôde ser arquivado. O Quadro 3 apresenta a comparação entre o sistema atual de fechadura do forno modelo EC-10 e o sistema proposto. Para monitorar o trabalho, toda a sua condução foi registrada na forma desenhos virtuais, fotos e vídeos, visando análise posterior.

\subsubsection{Medir e testar (informações sobre os componentes)}

Nesta fase, identificou-se a aplicabilidade do DFMA durante as análises dos componentes, observando:

- desgastes prematuros;

- redução do número de componentes;

- materiais alternativos;

- equipamentos necessários para a manufatura, qualidade e manuseios; e

- layout do chão de fábrica.

O funcionamento das fechaduras usadas na empresa foi observado nos próprios fornos. A fechadura alemã foi observada quanto ao funcionamento, pois pôde ser montada no seu forno de origem. Para a fechadura italiana, foi possível apenas a observação por meio de um simples encaixe manual.

As análises de aplicabilidade do DFMA foram feitas e, como a empresa não fabrica os componentes da fechadura, foi solicitado o auxílio de profissionais especializados em processos de fabricação desse 
Quadro 3. Comparação entre sistema atual e proposto para fechadura do forno.

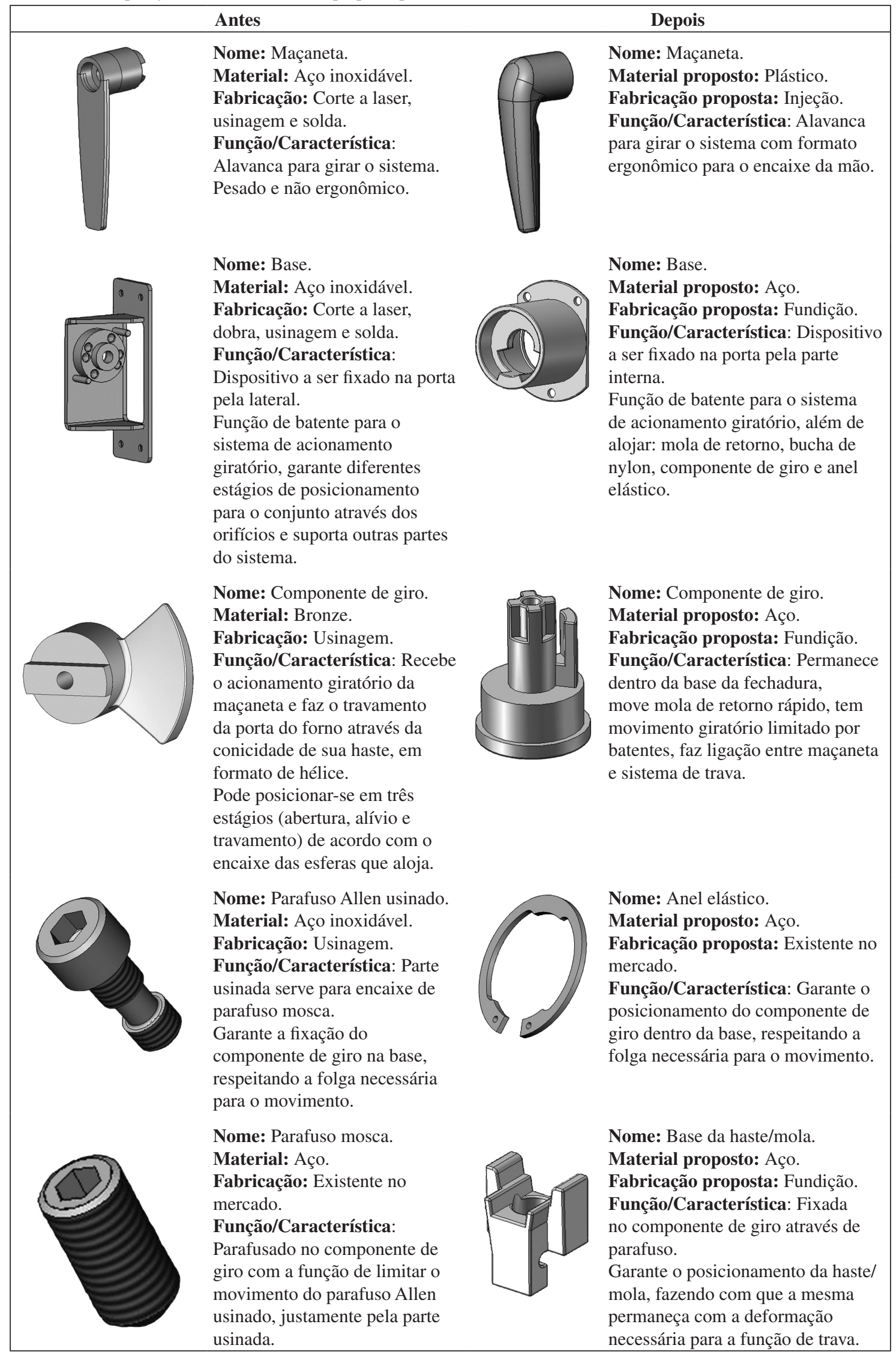


Quadro 3. Continuação.

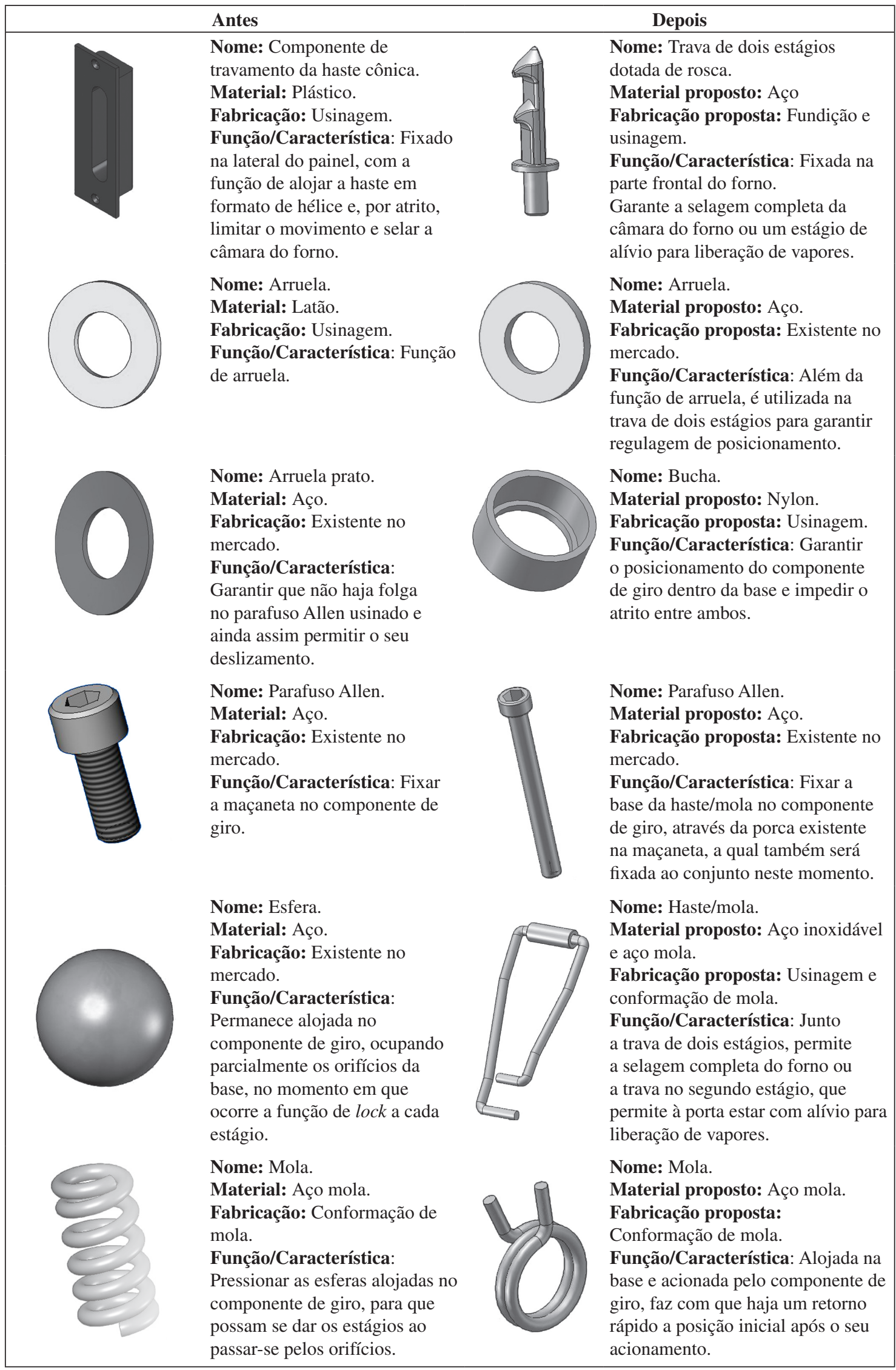


tipo de peças que trabalham em duas empresas que comercializam serviços de usinagem na região.

\subsubsection{Especificar e documentar}

A proposta da nova fechadura foi modelada por meio do software SolidWorks (versão 2005) e, levando em consideração as informações obtidas pelas fases anteriores, o novo produto foi definido. Cada um dos novos componentes foi desenhado e devidamente registrado e documentado.

\subsubsection{Prototipar}

Todas as peças da fechadura foram prototipadas na Universidade Federal de Itajubá (UNIFEI), na máquina Dimension SST 768, pelo método de Modelagem por Deposição de Material Fundido (FDM), como ilustra a Figura 5.

\subsubsection{Analisar e rever os resultados}

Assim como descrito na literatura, o projeto passou por todas as fases anteriores e, ao final delas, o protótipo pôde ser apresentado para a equipe formada para a pesquisa.

Foram identificadas novas necessidades, fazendo o projeto retornar a algumas das fases anteriores para reavaliação e reprojeto. Depois de repetir esse ciclo por diversas vezes, finalmente chegou-se a um projeto conceitual final, mostrado na Figura 6.

\section{Análise dos resultados}

Segundo Coughlan e Coghlan (2002), o aspecto crítico da análise de dados na pesquisa-ação é que ela é colaborativa, tanto o pesquisador quanto os membros do sistema cliente (por exemplo, o time de gerentes, um grupo de clientes etc.) fazem-na juntos. Esta abordagem colaborativa é baseada na suposição de que os colaboradores conhecem melhor a sua empresa, sabem o que irá funcionar e, principalmente, serão aqueles que irão implementar e seguir as ações a serem implementadas. Portanto, seu envolvimento na análise é crucial.

Sendo assim, os critérios e ferramentas para a análise foram discutidos entre o pesquisador e sua equipe de colaboradores da empresa, de forma a estarem diretamente ligados ao propósito da pesquisa e no âmago das intervenções.

Foram identificados 12 aspectos para a comparação dos resultados finais entre o sistema atual de fechadura e o novo sistema proposto. A Tabela 1 apresenta de forma resumida esses aspectos.

A fechadura atual possui 13 componentes, pois são necessárias duas esferas e duas molas. Isso já não é necessário na nova fechadura, que contém apenas 11 componentes, representando uma redução aproximada de $15 \%$ no número de componentes.

Para a fabricação da fechadura atual, são utilizados cinco processos de fabricação: corte a laser, dobra, usinagem, solda e conformação de mola. Já para a fechadura nova, propõem-se apenas quatro: injeção de plástico, usinagem, conformação de mola e fundição, ou seja, uma redução de $20 \%$ no número de processos.

O tempo de fabricação da fechadura atual foi obtido do fornecedor que produz o produto, englobando todos os processos de corte a laser, dobra, usinagem, solda, conformação de mola e acabamento, resultando em um tempo total de 220 minutos. Além da fabricação, a montagem do conjunto também é feita por este fornecedor e são necessários, aproximadamente, 480 segundos para a fechadura estar pronta para despacho. O custo de todo este serviço é de $\mathrm{R} \$ 124,00$.

Fazendo contado com os fornecedores, discutindo métodos de produção e fazendo estimativas para a nova fechadura, pôde-se estimar os custos em, aproximadamente, $\mathrm{R} \$ 45,00$ (redução de $64 \%$ no custo), englobando todas as peças necessárias e o tempo para fabricação das peças manufaturadas em, aproximadamente, 20 minutos (redução de $91 \%$ no tempo de fabricação). Por meio da montagem de protótipos usinados, estima-se um tempo de 150 segundos (redução de 68\%) para a montagem do sistema.

Por meio do sistema de atendimento ao consumidor (SAC) e pessoal de assistência técnica foi possível identificar alguns problemas apresentados pela fechadura atual:

- processo de fabricação caro, devido à quantidade e complexidade da usinagem de alguns componentes;

- sobra de material (sucata);

- com o passar do tempo ou utilização excessiva, o sistema gera uma folga, ocasionada pelo desgaste, dado pela alavanca que pressiona o conjunto a todo fechamento da porta;

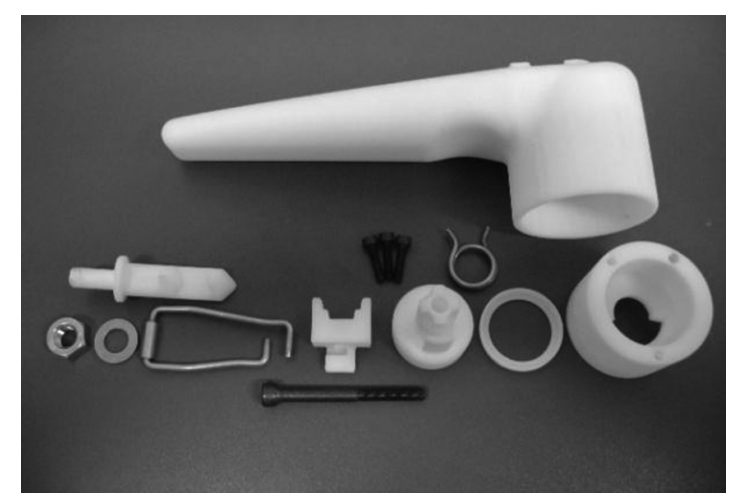

Figura 5. Peças prototipadas do sistema de fechadura proposto. 
- por ser um sistema que trava a porta pelo atrito entre duas partes, até que ambas encaixem-se, é necessário fazer certa força para superar esse atrito, tornando o sistema duro;

- não existe nenhum sistema de retorno por mola para auxiliar os movimentos;

- o alívio existente gera uma abertura muito pequena entre a porta e a guarnição que, às vezes, não é percebido pelo cliente e, portanto, não utilizado. Também pode não ser utilizado quando o cliente o considera ineficiente para liberação do vapor;

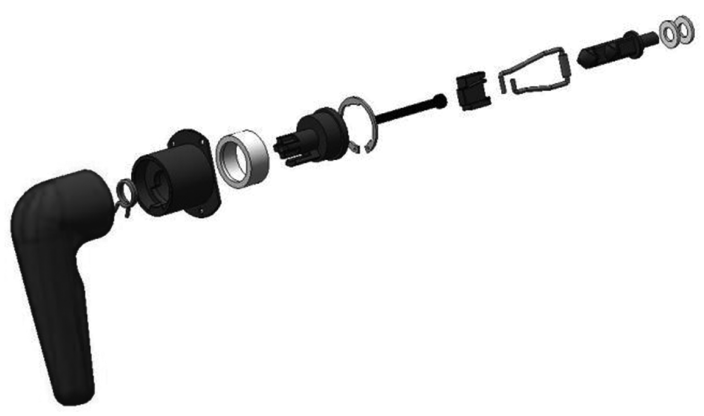

Figura 6. Vista explodida do projeto conceitual proposto para sistema de fechadura.
- o sistema é complicado para montagem e desmontagem, devido à presença de parafuso mosca, esferas e molas, que podem não ser utilizados de maneira correta por uma pessoa leiga. Geralmente, quando ocorre folga, é necessária a troca da fechadura inteira;

- por ser feita pela união de chapas de três milímetros, gerando um cabo de seis milímetros, os cantos acabam ficando retos, o que torna o manuseio doloroso, já que há a necessidade de se fazer força em cima de uma aresta; e

- se a fechadura, após a abertura, for retornada à posição vertical e depois for feito o fechamento do forno, o componente de giro irá bater no painel e, provavelmente, amassar.

Após os primeiros testes com a fechadura nova, foi possível chegar a conclusões preliminares quanto a algumas dificuldades: por ser um sistema em que a haste/mola deve encaixar-se perfeitamente na trava, é necessário ter maior atenção no posicionamento da porta, garantindo o alinhamento correto; se, devido à construção do forno, houver algum erro de dimensões, o que ocorre com certa frequência (devido à existência de processos como puncionamento, dobra, encaixe sem gabaritos e solda), deve-se fazer uso de arruelas para o posicionamento correto da trava de

Tabela 1. Análise comparativa dos resultados finais do projeto do sistema de fechadura.

\begin{tabular}{lcc}
\hline \multicolumn{1}{c}{ Requisito } & Antes & Depois \\
\hline Quantidade de componentes & 13 & 11 \\
$\begin{array}{l}\text { Quantidade de processos de } \\
\text { fabricação }\end{array}$ & 5 & 4 \\
$\begin{array}{l}\text { Tempo de fabricação de peças } \\
\text { manufaturadas (minutos) }\end{array}$ & 220 & 20 \\
$\begin{array}{l}\text { Custo do produto (R\$) } \\
\text { Tempo de montagem do sistema } \\
\text { (segundos) }\end{array}$ & 124,00 & 45,00 \\
Dificuldades/Problemas & 480 & 150 \\
Benlicios & 7 & 3
\end{tabular}

\section{Benefícios}

Manutenção

Funções

Funcionamento

Sistema do alívio

Ergonomia
Sistema robusto; atende às exigências como fechadura e consolidado na empresa.

Difícil; geralmente o sistema é trocado por inteiro. 3

Abertura: 90 graus à esquerda; média força.

Alívio: 45 graus à esquerda; média força.

Fechamento: Pressão na porta e 90 graus à direita; grande força. Ineficiente.

Mecanismo duro; maçaneta com cantos retos.
Fechadura inovadora; de fácil utilização e bons recursos.

Fácil montagem e desmontagem.

Abertura: 50 graus à esquerda ou à direita e mantém; pequena força.

Alívio: 50 graus à esquerda ou à direita e solta; pequena força.

Fechamento: Leve pressão ou pela batida da porta.

Possibilita um alívio de 20 milímetros.

Mecanismo leve; maçaneta arredondada. 
dois estágios; como algumas peças propostas serão fundidas, é necessário um grande desembolso inicial para a fabricação dos moldes de fundição, tanto para o metal quanto para o plástico, num total de aproximadamente $\mathrm{R} \$ 35.000,00$.

Em contrapartida a essas dificuldades, foi possível observar os benefícios de cada fechadura. A atual possui um sistema robusto, que atende às exigências do mercado e está consolidada na empresa. A nova proposta é inovadora (em relação aos modelos utilizados na empresa), de fácil utilização e bons recursos.

O sistema atual é de difícil manutenção, uma vez que dificilmente a troca de alguma peça resolve o problema. Geralmente, o sistema é substituído por inteiro, além da complexidade para montagem e desmontagem. A fechadura nova é de fácil desmontagem e montagem: as principais peças podem ser trocadas com a retirada de apenas um parafuso. Possui menor desgaste, pois o sistema sofre principalmente força axial.

Em relação às funções, é possível observar na atual fechadura as seguintes: garantir a selagem completa do forno; disponibilizar sistema de alívio; servir como haste para abertura e fechamento do forno. As funções da fechadura nova contemplam as funções do sistema atual e ainda: abrir o forno com o giro da maçaneta, tanto para a direita, quanto para a esquerda; garantir o retorno rápido da maçaneta, após ser acionada.

No que tange ao funcionamento, pôde-se verificar uma melhoria em relação à abertura, alívio e fechamento.

O sistema de alívio da fechadura atual é considerado ineficiente, já que proporciona distância muito pequena para liberação de vapores, geralmente imperceptível pelos clientes. O sistema de alívio da fechadura nova possibilita um alívio de $20 \mathrm{~mm}$, podendo ser utilizado com um leve toque na maçaneta. Ele pode não ser utilizado por opção, caso a maçaneta seja acionada e permaneça com 50 graus de torção durante a abertura.

A nova fechadura possibilita o fechamento (lock) da porta, se for deslocada com um leve jogo de corpo, em momentos em que o operador se encontra com as mãos ocupadas e não tem a intenção de deixar a porta do forno aberta.

Considerando a ergonomia, a atual fechadura é considerada pela equipe um mecanismo duro, necessitando de muita força para o acionamento. A maçaneta possui cantos retos que machucam com a utilização diária. Na nova fechadura o mecanismo é leve, pode ser acionado com um único dedo, é fácil de fechar e a maçaneta é arredondada para o encaixe da mão.

Após obter todas as peças em materiais suficientemente resistentes para testar o mecanismo, foi feita uma reunião com todos os responsáveis da equipe para um teste. A Figura 7 ilustra o protótipo pronto para teste.

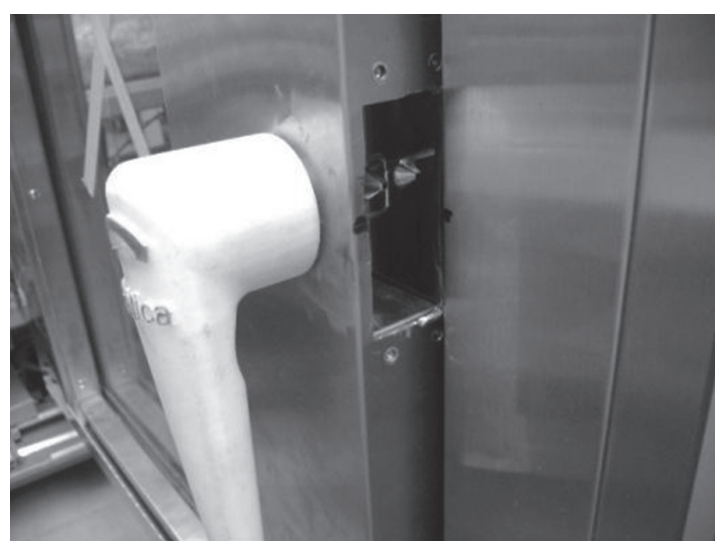

Figura 7. Fechadura nova montada para teste.

Com a utilização de uma nova porta com a furação adequada para nova fechadura, montou-se o mecanismo no forno proposto e pode-se testar o funcionamento.

Todos os integrantes da equipe manusearam a fechadura de formas diferentes, de acordo com suas percepções de exigências que devem ser atendidas pelo produto.

A nova fechadura foi aprovada por todos, como se percebeu em alguns depoimentos. O Cozinheiro Chefe afirmou: "Para mim não faz muita diferença o tipo de fechadura, eu gosto do sistema atual mas, realmente, este novo ficou mais fácil". Já o responsável de Compras completou dizendo: "Gostei muito, agora temos que decidir os materiais, processos de fabricação e aonde vai ser feito. Estamos no caminho certo, os concorrentes estão trazendo coisas novas e essa fechadura vai dar um diferencial para o nosso forno". Finalmente, o Diretor da Fábrica completou: "O sistema ficou muito legal. Vamos definir se realmente fica finalizado nesse protótipo, mandar produzir mais protótipos funcionais e testar. Podemos utilizar acionadores pneumáticos para ver os desgastes e ir ajustando até que possa ser introduzido em nossa linha".

\section{Conclusões}

O trabalho realizado preocupou-se em chegar a um produto que atendesse às exigências da empresa e do mercado, trazendo inovações e soluções para problemas antigos. O projeto encontra-se em fase de testes, levando em conta pontos importantes listados pela equipe de projeto e com o intuito de identificar possíveis pontos para reprojeto. Pretende-se chegar a uma fechadura ideal e, em uma segunda fase, realizar análises financeiras para então programar fornecedores, modificar linhas de produção e componentes dos fornos para a utilização do novo sistema.

Analisando preliminarmente a diferença entre custo das fechaduras, tempo para fabricação, tempo 
para montagem e facilidades apresentadas pelo modelo novo, percebe-se que será uma mudança muito positiva e, embora se tenha altos custos com a aquisição dos moldes de fundição, com o tempo esse montante será recompensado.

Dessa forma, os objetivos do trabalho foram atingidos. Foram feitas as recomendações de melhorias no projeto conceitual do novo sistema de fechadura. Foi utilizado o modelo proposto por Souza (2007) que integra projeto para manufatura e montagem (DFMA) com a prototipagem rápida (PR) em uma abordagem da engenharia reversa (ER). Foram utilizadas fechaduras de referência, por meio da ferramenta ER, no momento da criação virtual da nova fechadura, conceitos de DFMA foram empregados para beneficiar o produto e a primeira análise física do sistema foi possível devido à fabricação do primeiro protótipo por PR, além de utilizar o modelo no decorrer do projeto, já que ele propõe retornar às fases anteriores sempre que for necessário.

Portanto, o presente trabalho contribuiu na consolidação do modelo proposto por Souza (2007), que se mostrou adequado para a criação desse novo projeto.

Como os princípios do DFMA não são estruturados, sugere-se para trabalho futuro uma pesquisa que trate justamente da estruturação dos princípios do DFMA para aplicação no desenvolvimento ou reprojetos de produtos industriais.

Espera-se que a nova fechadura venha a ser validada e que as melhorias beneficiem tanto a empresa quanto os seus clientes. Como sugestões para futuros trabalhos, sugere-se aplicar o modelo proposto por Souza (2007) no reprojeto de outros produtos para validar sua utilidade. Foi dada entrada no INPI de um pedido de patente de modelo de utilização para a fechadura proposta neste trabalho.

\section{Agradecimentos}

Os autores agradecem à Fapemig (processos EDT-538/07 e TEC-PPM-00043/08) os recursos fornecidos para o fomento de pesquisas sobre o presente tema, sem os quais a realização desta pesquisa não seria possível. Nosso muito obrigado também à Prática Technicook e aos seus colaboradores, que nos permitiram realizar o presente trabalho.

\section{Referências}

ARTIS. Tecnologias de prototipagem - estereolitografia SLA. Brasília, DF: Clínica de Odontologia Integrada Artis. Disponível em: <http://www.artis.com.br>. Acesso em: 25 maio 2006.

BACK, N. et al. Projeto integrado de produtos: planejamento, concepção e modelagem. Porto Alegre: Editora Manole, 2008.

BACK, N. Metodologia de projeto de produtos industriais. Rio de Janeiro: Guanabara Dois, 1983.
BAGCI, E. Reverse engineering applications for recovery of broken or worn parts and re-manufacturing: Three case studies. Advances in Engineering Software, v. 40, p. 407-418, 2009.

BOOTHROYD, G.; DEWHURST, P.; KNIGHT, W. Product development for manufacture and assembly. $2^{\text {nd }} \mathrm{ed}$. rev. exp. New York: Marcel Dekker, 2002.

BOURREAU, M.; DOGAN, P. Cooperation in product development and process R\&D between competitors. International Journal of Industrial Organization, 2009. Doi: 10.1016/j.ijindorg.2009.07.010.

BRYMAN, A. Research methods and organization studies (contemporary social research). London: Routledge, 1989.

CHEN, L. C. Reverse engineering in the design of turbine blades - a case study in applying the MAMDP. Robotics and Computer Integrated Manufacturing, v. 16, n. 2-3, p. 161-167, 2000.

CHOI, S. H.; CHAN, A. M. M. A virtual prototyping system for rapid product development. Computer-Aided Design, v. 36, p. 401-412, 2004.

COOPER, R. G.; EDGETT, S. J. Product Development for de Service Sector. Lessons from market leaders. New York: Basic Books, 1999.

COUGHLAN, P.; COGHLAN, D. Action research for operations management. International Journal of Operations \& Production Management, v. 22, n. 2, p. 220-240, 2002.

DUFOUR, C. A. Estudo do processo e das ferramentas de reprojeto de produtos industriais, como vantagem competitiva e estratégia de melhoria constante. 1996. 122 f. Dissertação (Mestrado)-Universidade Federal de Santa Catarina, Florianópolis, 1996.

ESTORILIO, C.; SIMIÃO, M. C. Cost reduction of a diesel engine using the DFMA method. Product Management \& Development, v. 4, n. 2, p. 95-103, 2006.

GAUTAM, N.; SINGH, N. Lean product development: Maximizing the customer perceived value through design change (redesign). International Journal of Production Economics, v. 114, p. 313-332, 2008.

HOBDAY, M.; RUSH, H.; BESSANT, J. Approaching the innovation frontier in Korea: the transition phase to leadership. Research Policy, v. 33, p. 1433-1457, 2004.

HUANG, G. Q.; MAK, K. L. Design for manufacture and assembly on the Internet. Computers in Industry, v. 38, p. 17-30, 1999.

HÜSIG, S.; KOHN, S. Computer aided innovation. State of the art from a new product development perspective. Computers in Industry, v. 60, p. 551-562, 2009.

INGLE, K. A. Reverse engineering. New York: McGrawHill, 1994.

KANG, Y.; PARK, C.; WU, C. Reverse-engineering 1-n associations from Java bytecode using alias analysis. Information and Software Technology, v. 49, p. 81-98, 2007.

KIM, L.; NELSON, R. Tecnologia, aprendizado e inovação: as experiências das economias de industrialização recente. Campinas: Unicamp, 2005. Edição do original estadunidense, 2000. 
KOCHAN, A. Rapid prototyping gains speed, volume and precision. Assembly Automation, v. 20, n. 4, p. 295-299, 2000.

MURY, L. G. M. Uma metodologia para adaptação e melhoria de produtos a partir da engenharia reversa. 2000. 89f. Dissertação (Mestrado em Engenharia de Produção) - Escola de Engenharia, Universidade Federal do Rio Grande do Sul, Porto Alegre, 2000.

OGLIARI, A. Sistematização da concepção de produtos auxiliada por computador com aplicações no domínio de componentes de plástico injetado. 1999. Tese (Doutorado) - Universidade Federal de Santa Catarina, Florianópolis, 1999.

PAHL, G. et al. Projeto na engenharia: fundamentos do desenvolvimento eficaz de produtos, métodos e aplicações. 6. ed. São Paulo: Edgard Blücher, 2005.

ROSENTHAL, S. R. Effective product design and development - how to cut lead time and increase customer satisfaction. New York: Irwin Professional Publishing, 1992.

ROZENFELD, H. et al. Gestão de desenvolvimento de produtos: uma referência para a melhoria do processo. São Paulo: Saraiva, 2006.

SALGADO, E. G. et al. Análise da aplicação do mapeamento do fluxo de valor na identificação de desperdícios do processo de desenvolvimento de produtos. Gestão e Produção, v. 16, n. 3, p. 344-356, 2009.
SILVA, C. E. S. Método para avaliação do desempenho do processo de desenvolvimento de produtos. 2001. Tese (Doutorado em Engenharia de Produção)-Universidade Federal de Santa Catarina, Florianópolis, 2001.

SOUZA, J. F. Aplicação de projeto para manufatura e montagem em uma abordagem de engenharia reversa: estudo de caso. 2007. 135f. Dissertação (Mestrado em Engenharia de Produção)-Universidade Federal de Itajubá, Itajubá, MG, 2007.

STEPHENSON, J.; WALLACE, K. Design for reability in mechanical systems. In: INTERNATIONAL CONFERENCE ON ENGINEERING DESIGN - ICED, 95., 1995, Praha. Anais...

THIOLLENT, M. Metodologia da pesquisa-ação. 15. Ed. São Paulo: Cortez, 2007.

TOLEDO, J. C. et al. Práticas de gestão no desenvolvimento de produtos em empresas de autopeças. Produção, v. 18, n. 2, p. 405-422, 2008.

VINCENT, G. Managing new product development. New York: Van Nostrand Reinold, 1989.

WHEELWRIGHT, S. C.; CLARK, K. B. Revolutionizing product development - quantum leaps in speed, efficiency, and quality. New York: Free Press, 1992.

ZHU, J.; LIANG, X.; XU, Q. The cause of secondary innovation dilemma in chinese enterprises and solutions. In: INTERNATIONAL ENGINEERING CONFERENCE - IEEE, 2005. Proceedings... 2005. v. 1, p. 297-301. 